\title{
Maltreatment during childhood and risk for common mental disorders among first year university students in South Africa
}

\author{
Bronwyn Myers $^{1,2}$ (1) $\cdot$ Jason Bantjes ${ }^{3} \cdot$ Christine Lochner $^{4} \cdot$ Phillippe Mortier $^{5,6,7} \cdot$ Ronald C. Kessler $^{8} \cdot$ Dan J. Stein $^{2,9}$
}

Received: 4 June 2020 / Accepted: 10 November 2020 / Published online: 4 January 2021

c) Springer-Verlag GmbH Germany, part of Springer Nature 2021

\begin{abstract}
Purpose Childhood maltreatment elevates risk for common mental disorders (CMDs) during late adolescence and adulthood. Although CMDs are highly prevalent among university students, few studies have examined the relationship between childhood maltreatment and 12 month CMDs in a low- to middle-income countries. This paper describes the prevalence of maltreatment and the relationship between type, number and patterns of maltreatment exposure and 12 month CMDs among first-year university students in South Africa.

Methods Maltreatment and CMD data were collected via well-validated self-report scales (corresponding with DSM-IV diagnoses) in a web-based survey of first-year students from two large urban universities $(n=1290)$ in South Africa. Various multivariate modelling approaches (additive, restrictive interactive and latent class) were used to examine the relationship between maltreatment and CMDs.

Results Overall, $48.4 \%$ of participants reported childhood maltreatment, the most common type being emotional abuse (26.7\%). Regardless of the modelling approach used, emotional abuse was the only type of maltreatment independently associated with 12-month diagnoses of major depressive disorder (MDD), generalised anxiety disorder (GAD) or drug use disorder (DUD) even after adjusting for types and number of types of maltreatment. Similarly, students in the latent class reflecting histories of emotional abuse (either alone or combined with physical abuse) were more likely to meet criteria for 12-month MDD, GAD or DUD.

Conclusion Findings confirm the high prevalence of childhood maltreatment among South African students. As this exposure elevates risk for MDD, GAD and DUD, interventions aimed at preventing and treating CMDs among first-year students should address experiences of childhood maltreatment.
\end{abstract}

Keyword Childhood maltreatment $\cdot$ Emotional abuse $\cdot$ Common mental disorders $\cdot$ University students $\cdot$ South africa

Electronic supplementary material The online version of this article (https://doi.org/10.1007/s00127-020-01992-9) contains supplementary material, which is available to authorized users.

Bronwyn Myers

bmyers@mrc.ac.za

1 Alcohol, Tobacco and Other Drug Research Unit, South African Medical Research Council, PO Box 19070, Tygerberg 7505, South Africa

2 Department of Psychiatry and Mental Health, University of Cape Town, Cape Town, South Africa

3 Institute for Life Course Health Research, Department of Global Health, Stellenbosch University, Private Bag X1, Matieland 7602, South Africa

4 SAMRC Unit On Risk and Resilience in Mental Disorders, Department of Psychiatry, Stellenbosch University, Stellenbosch, South Africa
5 Group Health Services Research Group, IMIM (Hospital del Mar Medical Research Institute), Barcelona, Spain

6 CIBER Epidemiología y Salud Pública (CIBERESP), Madrid, Spain

7 Research Group Psychiatry, Department of Neurosciences, KU Leuven University, Leuven, Belgium

8 Department of Health Care Policy, Harvard Medical School, Harvard University, Boston, MA, USA

9 SAMRC Unit on Risk and Resilience in Mental Disorders, Department of Psychiatry and Mental Health, University of Cape Town, Cape Town, South Africa 


\section{Introduction}

Starting university coincides with young people's developmental transition from adolescence into adulthood [1]. This is also a peak time for the onset of common mental disorders (CMDs), such as depressive, anxiety, and substance use disorders (SUD) [2]. Studies from high-income countries suggest that CMDs are considerably more prevalent among university students than the general population, partly because of heightened stress associated with social and academic transitions from school to university [3-5]. Similar findings have been reported for South Africa, a low- to middle-income country (LMIC), where lifetime and 12 month prevalence estimates for any CMD among university students are $39 \%$ and $32 \%$, respectively [6] - higher than the $30 \%$ and $17 \%$ reported for the general population [7]. These prevalence estimates are comparable with those found among university students in other countries [8,9] and are of global concern given the deleterious effects that untreated CMDs have on students' academic performance [8-10], social functioning and quality of life $[11,12]$, self-harm, and death by suicide [13-16].

The design of effective mental health interventions requires reliable epidemiological data on risk factors for CMDs [6, 17]. Yet information on risk factors for CMDs among South African university students has been limited to socio-demographic correlates [6]. In keeping with studies from other contexts [13,17], findings suggest that vulnerability for CMDs is heightened among students who identify as female, report a non-heterosexual sexual orientation, or have disabilities [6]. Social and contextual factors, such as poverty and social disadvantage, which could plausibly enhance risk for CMDs among South African students remain underexplored [18]. Maltreatment during childhood (such as neglect, physical abuse, sexual abuse, or emotional abuse) is one such factor, with evidence suggesting that maltreatment elevates risk for CMDs in late adolescence and adulthood [19, 20]. Child maltreatment is a form of childhood adversity which captures a broader range of circumstances and events that threaten a child's physical and psychological well-being [19]. Findings from multiple studies demonstrate that any type of maltreatment in childhood increases risk for the internalising (mood and anxiety) disorders [20-27]. Although any maltreatment exposure heightens risk, findings from systematic reviews suggest that emotional abuse may have powerful effects on risk for depression and anxiety disorders compared to other forms of maltreatment [24, 28-31]. Similarly, findings from nationally representative surveys and birth cohort studies suggest that childhood maltreatment increases risk for SUDs in later life [32-34]. However, when SUDs are disaggregated into alcohol use disorders
(AUD) and drug use disorders (DUD), this relationship is most salient for DUD [21, 32, 33, 35]. Several studies have found no or only weak associations between childhood maltreatment and AUD [20, 21, 35-37].

Despite evidence linking childhood maltreatment to adverse mental health outcomes, knowledge gaps remain. Studies that focused on the association of such outcomes with individual subtypes (e.g. sexual abuse) or the presence of any type of maltreatment did not account for the potential co-occurrence of maltreatment types and may have overestimated the strength of the associations between specific types of maltreatment and CMDs [20,38-40]. Other studies attempted to assess the combined effect of multiple types of maltreatment by constructing a score reflecting the number of maltreatment types that a person was exposed to. While studies using this approach have shown that being multiply maltreated increases risk for depression, anxiety, and SUD [40, 41], they provide little insight into the patterning of multiple maltreatment exposures and if these patterns have differential effects on vulnerability for CMDs. More recently, studies have used latent class analysis to identify constellations of maltreatment experiences and explore how each of these patterns relates to CMD risk [36-39]. Although some of these studies have focused on university students as a population of interest, all prior studies were conducted in high-income countries [38, 42-44]. Findings may not extend to LMICs with different socio-political contexts and more adversity. South Africa is a highly violent society, with South African children exposed to disproportionally high levels of maltreatment compared to global estimates [45]. With South Africa having a higher 12-month prevalence of CMDs among both university students and the general population [6,7] relative to most other countries [46], the relationship between maltreatment in childhood and CMDs warrants further investigation in this setting and population.

This paper addresses these gaps through simultaneously evaluating the independent association of specific forms of maltreatment, the cumulative risk of multiple forms of maltreatment, and the association of patterns of multiple maltreatment exposure and CMDs among South African first-year university students. More specifically, this paper aims to (1) describe the prevalence and co-occurrence of each type of maltreatment and (2) examine various models of the relationship between maltreatment and 12 month CMDs among first-year university students.

\section{Methods}

This paper presents cross-sectional data from a survey of student health conducted at Stellenbosch University and the University of Cape Town, situated within the Western Cape province of South Africa. The study was part of the World 
Health Organization's (WHO) World Mental Health Surveys: International College Student Project (WMH-ICS) [12, 17]. Methods are described in detail elsewhere [6].

\section{Participants and procedure}

All first-year students at Stellenbosch University in 2015 and 2017 and the University of Cape Town in $2017(n=14,575)$ were sent an email invitation to participate in the study. The email invitation contained a description of the study and a link to an anonymous online survey. Only students aged 18 or older who were enrolled for the first time at university were eligible to participate. In total, 1407 students completed the survey (representing a response rate of 9.7\%); 117 participants were excluded from the current analyses due to missing data on childhood maltreatment variables. The final sample for the present analyses comprised 1290 participants. Participants were predominantly female $(n=715 ; 55.4 \%)$, self-identified as White $(n=785 ; 60.9 \%)$, and younger than 21 years of age $(n=1197 ; 92.9 \%)$.

\section{Measures}

Items adapted from the Composite International Diagnostic Interview (CIDI) used in the World Mental Health (WMH) Surveys [47] and various validated screening instruments were used to assess:

\section{Childhood maltreatment}

Selected items from the CIDI-3.0 childhood section [47] and the Adverse Childhood Experiences International Questionnaire [48] were used to measure four types of maltreatment prior to the age of 17. Emotional abuse was measured by three items assessing the frequency with which caretakers insulted, said hurtful things, or emotionally abused participants. Physical abuse was measured by two items examining the frequency with which caregivers pushed, hit, or bruised the participant. Neglect was assessed with two questions about physical neglect and endangerment, including frequency of having inadequate supervision and having to do dangerous, age-inappropriate tasks. Sexual abuse was assessed by two items enquiring about experiences of sexual assault, unwanted sexual contact or abuse. Response options consisted of five-point Likert items ("never", "rarely", "sometimes", "often", and "very often"). Consistent with previous WMH survey studies [49, 50], physical abuse, sexual abuse and neglect (endangerment) were coded as present if participants reported any exposure to these experiences. Emotional abuse was coded as present if respondents reported that they occurred sometimes, often, or very often. This type of maltreatment was coded differently as emotional abuse is dimensional in nature and the threshold is higher for it to qualify as maltreatment. This approach to coding is standard for studies of childhood maltreatment [49].

\section{Common mental disorders}

We used items adapted from the EPI-Q Screening Survey [51], WMH-CIDI [47], and Alcohol Use Disorders Identification Test [52] to assess the 12-month prevalence of Major Depressive Disorder (MDD), Generalised Anxiety Disorder (GAD), AUD, and DUD. These measures map onto DSMIV diagnostic criteria [47]. Due to low 12-month prevalence [12] and because GAD was the most prevalent 12 month disorder in the South African cohort, other anxiety disorders were excluded from the analyses. Caseness was determined using the procedure validated in the Army Study to Assess Risk and Resilience in Service Members (Army STARRS) [53] and replicated in the WMH Surveys.

\section{Data analysis}

As White and female students were over-represented in this sample, post-stratification weighting by population group and gender was conducted to minimise discrepancies between characteristics of the university population and those of the realized sample (see [54] for a description of these procedures). Data were analysed with SPSS. We used multiple imputation to address missing values for current AUD in the 2017 sample because questions about age of onset and current symptoms for AUD were erroneously omitted from the 2017 survey. This meant that $50 \%$ of participants had imputed data on AUD. First, we estimated the prevalence (95\% confidence intervals (CIs)) of each type of maltreatment for the overall sample and by gender. We then examined the correlations among the four types of maltreatment using tetrachoric correlations. Next, we conducted a series of multivariate logistic regression models to estimate the association between maltreatment and risk of any 12-month CMD and specific types of CMD. All models were adjusted for gender given its association with 12-month CMD diagnoses in this population [6] and risk of maltreatment [25]. The first model estimated the effect of each type of maltreatment independently, using separate regression equations for type of CMD. The second model estimated the additive effect of all four types of maltreatment within a single model.

We used MPlus [55] to conduct latent class analysis (LCA) to identify patterns of maltreatment exposure. Competing solutions were compared on model fit and conceptual interpretability of derived classes. Fit statistics that were considered included the log-likelihood, Akaike information criteria, Bayes information criteria (BIC), entropy, and Lo-Mendell-Rubin (LMR) adjusted likelihood ratio 
test. LMR was prioritized given evidence that it is one of the most robust measures of model fit [56]. We identified a three-class model as optimal, this model had a lower AIC than the two-class solution, with a significant LMR ( $p=0.017)$ test. Participants reporting no maltreatment were isolated into a separate fourth class. In Model 3, we examined the relationship between these four classes on risk of 12-month CMD diagnoses. As few differences were noted between Class 3 and Class 4, we constructed a restricted model that included Classes 2 and 4 and a combined term for group membership in Class 3 or 4 (Model 4). Based on the findings, we decided to test a more restricted model (Model 5) that excluded Class 4.

Following this, we conducted a sixth model which included variables assessing the number of types of abuse experienced (that is, variables assessing exposure to exactly one type, exactly two types, and exactly three types of abuse). In a seventh model, we included variables for the four types of maltreatment in addition to variables for the number of types of abuse experienced. In this restricted interactive model, the number of types of abuse started at exactly two rather than exactly one because the value of the variable for exactly one type of abuse was perfectly predicted by the three variables for emotional, physical and sexual abuse. Each of these models was estimated for any 12 month CMD diagnosis and again separately for each type of disorder [that is, MDD, GAD, an internalising disorder (i.e. MDD and/or GAD), AUD, DUD, and an externalising disorder (i.e. AUD and/or DUD)]. Findings are presented as odds ratios (OR) with $95 \%$ CI. Multivariate significance was examined using design-based Wald $\mathrm{X}^{2}$ tests. All significance tests were evaluated using 0.05 level two-sided tests.

\section{Results}

\section{Prevalence and correlations between types of child maltreatment}

Overall, $48.4 \%$ (95\% CI 45.7; 51.2) of the sample reported experiencing maltreatment during childhood. The most common form of child maltreatment was emotional abuse (26.7\%), followed by physical abuse $(20.8 \%)$, neglect $(10.7 \%)$ and sexual abuse $(4.3 \%)$. The prevalence of various types of maltreatment did not differ between men and women. Most of the tetrachoric correlations between pairs of maltreatment types were positive, illustrating high cooccurrence between various forms of maltreatment. Overall, $41.0 \%$ (95\% CI 38.2; 43.8) of the sample reported exposure to at least one form of abuse (emotional, sexual or physical), $31.5 \%$ reported exposure to exactly one form, $8.1 \%$ to exactly two types, and $1.4 \%$ reported exposure to exactly three types of abuse (Table 1).

\section{Associations between child maltreatment types and 12 month CMD diagnoses}

In Model 1, where the effect of each maltreatment type was estimated separately for 12 month CMD diagnoses, only physical abuse $(\mathrm{OR}=1.4)$ and emotional abuse $(\mathrm{OR}=2.1)$ were significantly associated with elevated risk of any 12 month CMD. When we disaggregated CMD diagnosis by class of disorder, physical abuse and emotional abuse were associated with elevated risk of a 12 month internalising disorder and emotional abuse was associated with risk of an externalising disorder. Sexual abuse $(\mathrm{OR}=2.1)$, physical abuse $(\mathrm{OR}=1.7)$, and emotional abuse $(\mathrm{OR}=2.7)$ were associated with risk of 12 month MDD, and physical abuse $(\mathrm{OR}=1.4)$ and emotional abuse $(\mathrm{OR}=2.3)$ were associated with risk of 12 month GAD (Table 2). Physical abuse $(\mathrm{OR}=2.1)$ and emotional abuse $(\mathrm{OR}=4.5)$ were associated with elevated risk of 12-month DUD but not AUD.

In Model 2, which included all forms of child maltreatment as predictors and corrected for the inflation of the effects arising from co-occurrence of maltreatment types, emotional abuse was the only type of maltreatment independently associated with heightened risk of any 12 month CMD, internalising disorder, MDD, and GAD (ORs ranged 2.1-2.5; Table 2). Physical abuse approached significance for each of these disorders. The $\chi_{4}^{2}$ test for the joint effects of all maltreatment types was significant for any CMD $\left(\chi_{4}^{2}=19.6\right.$, $p<0.01)$, any internalising disorder $\left(\chi_{4}^{2}=28.42, p<0.001\right)$, $\operatorname{MDD}\left(\chi_{4}^{2}=36.6, p<0.001\right)$ and $\operatorname{GAD}\left(\chi_{4}^{2}=13.8, p<0.01\right)$. Similarly, emotional abuse was the only type of maltreatment independently associated with heightened risk of any 12 month externalising disorder $(\mathrm{OR}=1.6)$ and DUD $(\mathrm{OR}=4.3)$. The $\chi^{2}{ }_{4}$ test for the joint effects of all maltreatment types was significant for DUD $\left(\chi_{4}^{2}=12.1, p<0.05\right)$.

\section{Associations between classes of child maltreatment and 12 month CMD diagnoses}

LCA identified four patterns of child maltreatment exposure. The most prevalent class (Class 1) was labelled ' $N o$ maltreatment' ( $n=665 ; 51.9 \%$ of the sample). Class $2(10.2 \%$ of sample), labelled 'Neglect', had the highest probability of endorsing neglect (0.99) and extremely low probabilities of physical, sexual or emotional abuse. Class 3, 'Emotional abuse' (21.1\% of sample), had high probabilities of exposure to emotional abuse $(0.84)$ and lower probabilities of exposure to physical or sexual abuse. Individuals in this class generally endorsed exposure to one form of abuse. In Class 4, labelled 'Multiple forms of abuse' (17.1\% of sample), individuals mainly endorsed physical and emotional abuse, although some reported exposure to three forms of abuse.

Model 3 examined associations between these latent classes and 12-month CMDs (Table 3). Odds of meeting 
Table 1 Prevalence and tetrachoric correlations of types of childhood maltreatment among South African university students $(n=1290)$

\begin{tabular}{|c|c|c|c|c|c|c|c|}
\hline \multirow{2}{*}{$\begin{array}{l}\text { Characteristics } \\
\text { of maltreatment } \\
\text { exposure }\end{array}$} & \multirow{2}{*}{$\begin{array}{l}\text { Prevalence total } \\
\text { sample } \\
(n=1290) \\
(\%, 95 \mathrm{CI})^{\mathrm{a}}\end{array}$} & \multirow{2}{*}{$\begin{array}{l}\text { Prevalence: women } \\
(n=860) \\
(\%, 95 \mathrm{CI})^{\mathrm{a}}\end{array}$} & \multirow{2}{*}{$\begin{array}{l}\text { Prevalence: men } \\
(n=430) \\
(\%, 95 \mathrm{CI})^{\mathrm{a}}\end{array}$} & \multicolumn{4}{|c|}{ Tetrachoric correlations (rho) } \\
\hline & & & & Neglect & Physical abuse & Sexual abuse & Emotional abuse \\
\hline \multicolumn{8}{|l|}{ Type of maltreatment } \\
\hline Neglect $(n=139)$ & $10.7 \%(9.1-12.6)$ & $11.7 \%(9.7-14.1)$ & $9.4 \%(7.0-12.7)$ & 1.00 & $0.48 * * *$ & $0.36^{* * *}$ & 0.02 \\
\hline $\begin{array}{l}\text { Physical abuse } \\
(n=269)\end{array}$ & $20.8 \%(18.6-23.2)$ & $20.1 \%(17.5-22.9)$ & $21.8 \%(18.1-25.9)$ & $0.48 * * *$ & 1.00 & $0.46^{* * *}$ & $0.25^{* * *}$ \\
\hline $\begin{array}{l}\text { Sexual abuse } \\
\quad(n=56)\end{array}$ & $4.3 \%(3.3-5.6)$ & $5.2 \%(3.9-6.9)$ & $3.2 \%(1.9-5.4)$ & $0.36 * * *$ & $0.46^{* * *}$ & 1.00 & 0.13 \\
\hline $\begin{array}{l}\text { Emotional abuse } \\
\quad(n=344)\end{array}$ & $26.7 \%(24.3-29.2)$ & $29.6 \%(26.6-32.8)$ & $23.0 \%(19.3-27.3)$ & 0.02 & $0.25 * * *$ & 0.13 & 1.00 \\
\hline $\begin{array}{l}\text { Any maltreatment } \\
\quad(n=625)\end{array}$ & $48.4 \%(45.7-51.2)$ & $50.6 \%(47.2-53.9)$ & $45.8 \%(41.1-50.5)$ & & & & \\
\hline \multicolumn{8}{|c|}{ Number of types of abuse ${ }^{b}$} \\
\hline $\begin{array}{l}\text { No abuse } \\
\quad(n=761)\end{array}$ & $59.0 \%(56.2-61.8)$ & $57.5 \%(54.2-60.8)$ & $60.9 \%(56.1-65.0)$ & & & & \\
\hline $\begin{array}{l}\text { Exactly one type } \\
(n=405)\end{array}$ & $31.5 \%(28.9-34.1)$ & $31.7 \%(28.6-34.9)$ & $31.2 \%(26.9-25.8)$ & & & & \\
\hline $\begin{array}{l}\text { Exactly two types } \\
\quad(n=109)\end{array}$ & $8.1 \%(6.8-9.8)$ & $9.2 \%(7.4-11.3)$ & $6.9 \%(4.9-9.7)$ & & & & \\
\hline $\begin{array}{l}\text { Exactly three types } \\
\quad(n=17)\end{array}$ & $1.4 \%(0.8-2.2)$ & $1.6 \%(0.1-2.8)$ & $0.1 \%(0.0-0.3)$ & & & & \\
\hline
\end{tabular}

$* * * p<0.001$

${ }^{\mathrm{a}} 95 \%$ confidence intervals

${ }^{b}$ The last four rows reflect the number of types of abuse (physical, sexual or emotional) participants had experienced, whether or not the person had also experienced neglect

criteria for a 12 month CMD, MDD, GAD or any internalising disorder were heightened for individuals in the 'Emotional Abuse' and the 'Multiple forms of abuse' classes (ORs between 1.5 and 2.9). For the externalising disorders, individuals in the 'Multiple forms of abuse' class had almost triple the odds of meeting criteria for a DUD compared to those in other classes. The $\chi^{2}{ }_{3}$ tests for the joint effects of these classes were significant for any CMD $\left(\chi_{3}^{2}=15.9\right.$, $p<0.01)$, any internalising disorder $\left(\chi^{2}{ }_{3}=28.1, p<0.001\right)$, $\operatorname{MDD}\left(\chi_{3}^{2}=34.2, \mathrm{p}<0.001\right)$ and $\operatorname{GAD}\left(\chi_{3}^{2}=18.8, p<0.01\right)$, but not for DUD (Table 4).

With few differences observed between Class 3 and 4, we combined these classes into a single category ('Emotional abuse alone or in combination with other types of abuse') and explored associations between Class 2, Class 3/4, Class 4 and the various CMDs (Model 4, Table 3). The odds of meeting criteria for a 12 month CMD, MDD, GAD or any internalising disorder were only heightened for individuals in the 'Emotional abuse alone or in combination with other types of abuse' class (ORs between 1.7 and 2.1). The $\chi^{2}{ }_{3}$ tests for the joint effects of these classes remained significant for any CMD $\left(\chi_{3}^{2}=10.6, p<0.05\right)$, any internalising disorder $\left(\chi_{3}^{2}=15.9, p<0.001\right), \operatorname{MDD}\left(\chi_{3}^{2}=21.3, p<0.001\right)$ and $\operatorname{GAD}\left(\chi_{3}^{2}=12.4, p<0.01\right)$. Finally, we modelled the effects of Class 2 and Class 3/4 on CMD outcomes (Model 5 , Table 3). The $\chi_{2}^{2}$ tests for the joint effects of these classes remained significant for any $\operatorname{CMD}\left(\chi_{2}^{2}=10.4, p<0.01\right)$, any internalising disorder $\left(\chi_{2}^{2}=15.8, \mathrm{p}<0.001\right)$, MDD $\left(\chi_{2}^{2}=21.3, p<0.001\right)$ and $\operatorname{GAD}\left(\chi_{2}^{2}=12.2, p<0.01\right)$. The BICs for this model were equal or higher in magnitude than those reported in the first two approaches, suggesting that this more parsimonious model is as good a fit for the data as Models 3 and 4. Findings suggest that exposure to emotional abuse, either alone or in combination with other forms of abuse, heightens vulnerability for CMDs, particularly internalising disorders.

\section{Associations between number of types of child maltreatment and 12 month CMD diagnoses}

In Model 6, we considered only number of types rather than specific types or classes of maltreatment (Table 4). Findings from this model suggest that risk of 12 month CMD increases with exposure to two types of abuse, particularly for MDD and GAD (ORs range from 2.2 to 3.1) and DUD $(\mathrm{OR}=6.6)$. Exposure to three types of abuse increased the odds of a 12 month MDD diagnosis more than sixfold $(\mathrm{OR}=6.3)$. The $\chi^{2}{ }_{3}$ test for the joint effects of number of 
Table 2 Associations between childhood maltreatment type and 12-month mental disorder diagnoses among South African university students $(n=1290)$

\begin{tabular}{|c|c|c|c|c|c|c|c|c|c|}
\hline \multirow[t]{2}{*}{$\begin{array}{l}\text { Type of } \\
12 \text { month } \\
\text { diagnoses }\end{array}$} & \multicolumn{4}{|c|}{$\begin{array}{l}\text { Model 1: effects of each type of maltreatment on mental } \\
\text { disorder outcomes } \\
\text { OR }^{\mathrm{a}, \mathrm{b}}(95 \% \mathrm{CI})^{\mathrm{e}}\end{array}$} & \multicolumn{5}{|c|}{$\begin{array}{l}\text { Model 2: additive model of type of maltreatment on common } \\
\text { mental disorder outcomes } \mathrm{a}, \mathrm{c} \\
\text { OR }(95 \% \mathrm{CI})\end{array}$} \\
\hline & $\begin{array}{l}\text { Neglect } \\
(n=139)\end{array}$ & $\begin{array}{l}\text { Physi- } \\
\text { cal abuse } \\
(n=269)\end{array}$ & $\begin{array}{l}\text { Sexual abuse } \\
(n=56)\end{array}$ & $\begin{array}{l}\text { Emotional } \\
\text { abuse } \\
(n=344)\end{array}$ & $\overline{\chi^{2}(4)}$ & $\begin{array}{l}\text { Neglect } \\
(n=139)\end{array}$ & $\begin{array}{l}\text { Physi- } \\
\text { cal abuse } \\
(n=269)\end{array}$ & $\begin{array}{l}\text { Sexual abuse } \\
(n=56)\end{array}$ & $\begin{array}{l}\text { Emotional } \\
\text { abuse } \\
(n=344)\end{array}$ \\
\hline $\begin{array}{l}\text { Any type of } \\
\text { common } \\
\text { mental } \\
\text { disorder } \\
(n=414)\end{array}$ & $\begin{array}{l}1.1 \\
(0.8-1.6)\end{array}$ & $\begin{array}{l}1.4^{*} \\
(1.0-1.8)\end{array}$ & $\begin{array}{l}1.2 \\
(0.7-2.1)\end{array}$ & $\begin{array}{l}2.1 * * * \\
(1.6-2.7)\end{array}$ & $19.6 * *$ & $\begin{array}{l}1.1 \\
(0.8-1.7)\end{array}$ & $\begin{array}{l}1.2 \\
(0.9-1.6)\end{array}$ & $\begin{array}{l}1.0 \\
(0.6-1.9)\end{array}$ & $\begin{array}{l}2.1 * * * \\
(1.1-1.8)\end{array}$ \\
\hline \multicolumn{10}{|c|}{ Internalising disorders } \\
\hline $\begin{array}{l}\text { Major } \\
\text { depressive } \\
\text { disorder } \\
\text { (MDD, } \\
n=190)\end{array}$ & $\begin{array}{l}1.7 \\
(0.9-3.0)\end{array}$ & $\begin{array}{l}1.7 * * \\
(1.2-2.3)\end{array}$ & $\begin{array}{l}2.1^{*} \\
(1.1-3.9)\end{array}$ & $\begin{array}{l}2.7 * * * \\
(1.9-3.7)\end{array}$ & $36.6 * * *$ & $\begin{array}{l}1.6 \\
(0.9-2.9)\end{array}$ & $\begin{array}{l}1.3 \\
(0.9-1.9)\end{array}$ & $\begin{array}{l}1.5 \\
(0.8-2.9)\end{array}$ & $\begin{array}{l}2.5 * * * \\
(1.8-3.4)\end{array}$ \\
\hline $\begin{array}{l}\text { Generalised } \\
\text { anxiety } \\
\text { disorder } \\
\text { (GAD, } \\
n=272)\end{array}$ & $\begin{array}{l}1.0 \\
(0.6-1.5)\end{array}$ & $\begin{array}{l}1.4^{*} \\
(1.0-1.9)\end{array}$ & $\begin{array}{l}1.5 \\
(0.9-2.8)\end{array}$ & $\begin{array}{l}2.3 * * * \\
(1.7-3.0)\end{array}$ & $13.8^{* *}$ & $\begin{array}{l}1.0 \\
(0.6-1.6)\end{array}$ & $\begin{array}{l}1.3 \\
(0.9-1.8)\end{array}$ & $\begin{array}{l}1.2 \\
(0.6-2.2)\end{array}$ & $\begin{array}{l}2.1 * * * \\
(1.6-2.8)\end{array}$ \\
\hline $\begin{array}{l}\text { MDD and/ } \\
\text { or GAD } \\
(n=354)\end{array}$ & $\begin{array}{l}1.1 \\
(0.7-1.6)\end{array}$ & $\begin{array}{l}1.4^{*} \\
(1.1-1.9)\end{array}$ & $\begin{array}{l}1.5 \\
(0.9-2.7)\end{array}$ & $\begin{array}{l}2.4 * * * \\
(1.9-3.2)\end{array}$ & $28.4 * * *$ & $\begin{array}{l}1.0 \\
(0.7-1.7)\end{array}$ & $\begin{array}{l}1.3 \\
(0.9-1.7)\end{array}$ & $\begin{array}{l}1.2 \\
(0.7-2.2)\end{array}$ & $\begin{array}{l}2.3 * * * \\
(1.8-3.0)\end{array}$ \\
\hline \multicolumn{10}{|c|}{ Externalising disorders } \\
\hline $\begin{array}{l}\text { Alcohol use } \\
\text { disorder } \\
\text { (AUD, } \\
n=75)\end{array}$ & $\begin{array}{l}1.2 \\
(0.5-2.7)\end{array}$ & $\begin{array}{l}0.7 \\
(0.4-1.5)\end{array}$ & $\begin{array}{l}0.5 \\
(0.1-2.3)\end{array}$ & $\begin{array}{l}0.7 \\
(0.4-1.3)\end{array}$ & 1.6 & $\begin{array}{l}1.4 \\
(0.6-3.3)\end{array}$ & $\begin{array}{l}0.9 \\
(0.5-1.6)\end{array}$ & $\begin{array}{l}0.5 \\
(0.1-2.5)\end{array}$ & $\begin{array}{l}0.8 \\
(0.4-1.4)\end{array}$ \\
\hline $\begin{array}{l}\text { Drug use } \\
\text { disorder } \\
\text { (DUD, } \\
n=39)\end{array}$ & $\begin{array}{l}1.1 \\
(0.4-3.1)\end{array}$ & $\begin{array}{l}2.1^{*} \\
(1.0-4.0)\end{array}$ & $\begin{array}{l}0.9 \\
(0.2-4.6)\end{array}$ & $\begin{array}{l}4.5 * * * \\
(2.3-8.7)\end{array}$ & $12.1 *$ & $\begin{array}{l}1.0 \\
(0.3-2.9)\end{array}$ & $\begin{array}{l}1.7 \\
(0.8-3.5)\end{array}$ & $\begin{array}{l}0.6 \\
(0.1-3.2)\end{array}$ & $\begin{array}{l}4.3^{* * *} \\
(2.2-8.4)\end{array}$ \\
\hline $\begin{array}{l}\text { AUD and/ } \\
\text { or DUD } \\
(n=103)\end{array}$ & $\begin{array}{l}1.4 \\
(0.6-2.4)\end{array}$ & $\begin{array}{l}1.2 \\
(0.7-1.9)\end{array}$ & $\begin{array}{l}0.7 \\
(0.2-2.2)\end{array}$ & $\begin{array}{l}1.7 * \\
(1.1-2.5)\end{array}$ & 2.6 & $\begin{array}{l}1.3 \\
(0.6-2.4)\end{array}$ & $\begin{array}{l}1.0 \\
(0.7-1.9)\end{array}$ & $\begin{array}{l}0.6 \\
(0.2-1.9)\end{array}$ & $\begin{array}{l}1.6^{*} \\
(1.1-2.5)\end{array}$ \\
\hline
\end{tabular}

*Significant at $p<0.05$

** Significant at $p<0.01$

$* * *$ Significant at $p<0.001$

${ }^{a}$ All models control for the potentially confounding effect of gender

${ }^{\mathrm{b}}$ Series of regression equations for each type of maltreatment on each class of disorder

${ }^{\mathrm{c}}$ Additive model in which all types of maltreatment were entered into the regression equations

${ }^{\mathrm{d}} \mathrm{OR}$ odds ratio

${ }^{\mathrm{e}} 95 \%$ CI $95 \%$ confidence interval

types of abuse was significant for any CMD $\left(\chi_{3}^{2}=26.9\right.$, $p<0.001)$, internalising disorders $\left(\chi^{2}{ }_{3}=42.0, p<0.001\right)$, $\operatorname{MDD}\left(\chi^{2}{ }_{3}=39.6, p<0.001\right), \operatorname{GAD}\left(\chi^{2}{ }_{3}=33.7, p<0.001\right)$, and DUD $\left(\chi^{2}{ }_{3}=18.0, p<0.001\right)$.

We estimated a model with the types of abuse in addition to the number of types of abuse (Model 7). Exposure to emotional abuse was independently associated with 12-month CMD, any internalising disorder, MDD, GAD and
DUD; with ORs ranging from 2.0 to 3.9 ; the $\chi_{3}^{2}$ test for the joint effects of type of abuse was significant for any CMD $\left(\chi^{2}{ }_{3}=21.0, p<0.001\right)$, internalising disorders $\left(\chi^{2}{ }_{3}=36.7\right.$, $p<0.001)$, MDD $\left(\chi^{2}{ }_{3}=17.2, p<0.01\right), \operatorname{GAD}\left(\chi^{2}{ }_{3}=38.0\right.$, $p<0.001)$ and DUD $\left(\chi^{2}{ }_{3}=12.3, p<0.01\right)$. In this model, the ORs for the abuse types were slightly lower than the ORs when variables for number of types of abuse were not included (Table 2), showing that failing to account for the 


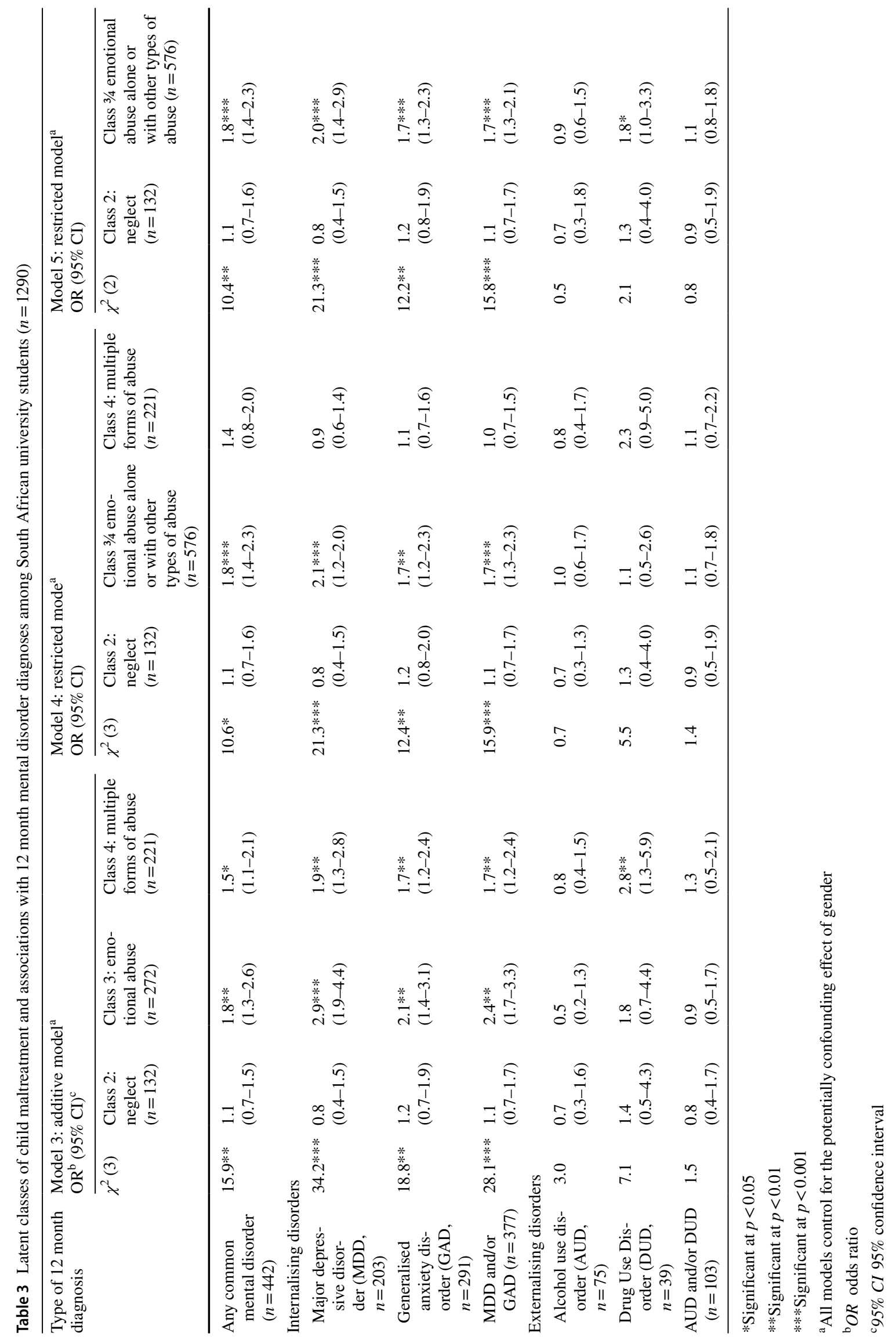




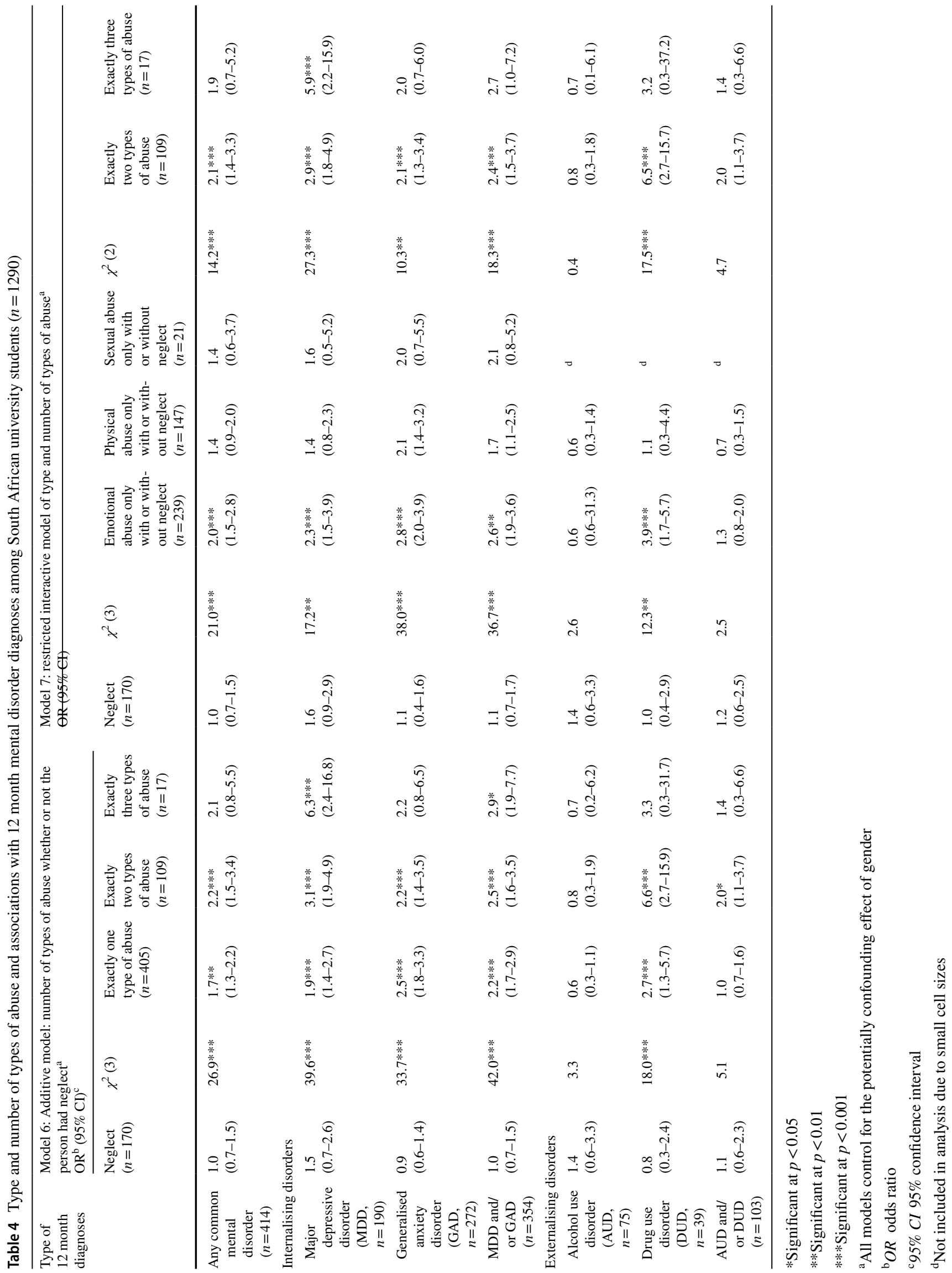


number of types of abuse may lead to an upward bias in the estimated effect of individual types of maltreatment. The ORs for the estimated effects of number of types of abuse were similar to the model that included number of types of abuse only (ORs between 2.1 and 6.5). The $\chi_{3}^{2}$ test for the joint effects of number of types of abuse was significant for any CMD $\left(\chi^{2}{ }_{2}=14.2, p<0.001\right)$, internalising disorders $\left(\chi_{2=}^{2} 18.3, p<0.001\right)$, MDD $\left(\chi_{2}^{2}=27.3, p<0.01\right)$, $\operatorname{GAD}\left(\chi_{2}^{2}=10.3, p<0.01\right)$ and DUD $\left(\chi^{2}{ }_{2}=17.5, p<0.01\right.$; Table 4).

\section{Discussion}

Although maltreatment during childhood is a recognised risk factor for mental disorder onset and persistence in the general population, it has only recently been explored among university students [42-44]—a population with heightened vulnerability for CMDs due to developmental transitions from adolescence to adulthood and social transitions from school to university [2,3]. To our knowledge, this is the first study examining the relationship between maltreatment during childhood and a range of 12 month CMDs in a large sample of university students in a LMIC. Findings underscore the high prevalence of child maltreatment in South Africa, with $48.4 \%$ of students reporting some form of maltreatment during childhood and $41.0 \%$ reporting that this maltreatment included emotional, physical and/or sexual abuse. These findings are in keeping with findings from nationally representative South African studies that over $40 \%$ of adolescents [45] and adults [20] experienced at least one form of maltreatment during childhood [20,45].

Like other studies from high-income countries [42-44], childhood maltreatment appears to heighten risk for any CMD among young South Africans entering university. When we disaggregated results by class of disorder, childhood maltreatment was associated with greater risk of all the 12 month internalising disorders and 12 month DUD. However, we found no evidence that childhood maltreatment was associated with risk of 12 month AUD. Our use of multiple imputation to account for missing alcohol use data for $50 \%$ of the sample may have influenced these findings. However, the literature suggests that the relationship between childhood maltreatment and SUDs is more salient for DUD than AUD [21, 32, 33, 35], with several studies from high-income countries reporting no or only weak associations between childhood maltreatment and AUD [20, 21, 35-37]. It is not clear why childhood maltreatment does not infer greater risk of AUD. One explanation is that there may be other, unmeasured environmental variables that inform whether childhood maltreatment presents risk for AUD during adulthood in the South African context. Additional qualitative work and prospective cohort studies are needed to identify conditions that mediate or moderate the relationship between child maltreatment and AUD (and other mental disorders) in this setting.

In keeping with findings from previous studies [20], exposure to more than one form of maltreatment increased risk for all the internalising disorders and DUD. In this study, emotional abuse (whether alone or in combination with other forms of abuse) had particularly deleterious effects on risk for MDD, GAD and DUD. Although aligned with findings from recent systematic reviews [24, 28-30], this study offers a unique perspective through using a variety of different modelling approaches (additive, restricted interactive, latent class) to examine the relationship between emotional abuse and risk of 12-month CMDs. Regardless of modelling approach, emotional abuse emerged as the only type of maltreatment independently associated with 12 month MDD, GAD and DUD even after adjusting for other types of maltreatment and number of types of maltreatment. Although physical abuse was associated with risk for 12 month MDD, GAD and DAD in bivariate analyses, this was not the case in the multivariate models. This suggests that the effect of physical abuse may be partially mediated by the co-occurrence of emotional abuse. Similarly, risk for these disorders was heightened among the latent class of students with histories of emotional abuse (either alone or in combination with physical abuse).

These findings are noteworthy as previous South African studies of childhood maltreatment have rarely examined the relationship between emotional abuse and mental health outcomes [20], possibly due to an assumption that other forms of abuse are intrinsically more detrimental. Our findings challenge this assumption. Although the multiple pathways through which emotional abuse may affect risk for MDD, GAD, and DUD remain unclear, one plausible explanation is that emotional abuse leads to emotional dysregulation and the development of negative self-schemas, i.e. cognitive structures associated with the onset and maintenance of depressive and anxiety disorders [57, 58]. Studies have illustrated how emotional abuse (but not other forms of maltreatment) contribute to the development of negative self-schemas and difficulties with emotional regulation, with negative self-cognitions mediating the relationship between emotional abuse and symptoms of depression and anxiety $[58,59]$. Emotional dysregulation has also been implicated in the development of DUD [60,61].

Our findings have implications for interventions to reduce 12 month prevalence of CMDs among South African university students. With findings suggesting that childhood maltreatment holds lasting risks for mental health, preventative strategies to reduce the prevalence of maltreatment in South Africa are urgently needed. Should recommendations to screen all first-year students for CMDs be implemented [6], exposure to emotional and other types of maltreatment 
should be assessed. Identifying students who may benefit from psychological interventions that provide strategies for reducing the harms associated with childhood maltreatment may be key to reducing the incidence of CMDs in this population. However, this screening is likely to identify a very large number of students who require these interventions; current mental health services available on South African university campuses are unlikely to cope with the increased demand for individual counselling services [62]. Although group therapy may be an alternative, this is not feasible in an era of COVID-19 where physical distancing is necessitated, unless groups are facilitated online. Another solution is to deliver self-guided internet-based interventions. There is strong evidence supporting the efficacy of self-guided internet-based cognitive behavioural therapy, which is considered an evidence-based treatment approach for addressing traumatic stress from experiences of maltreatment and internalising disorders $[63,64]$. With concerns about stigma and the disclosure of maltreatment being commonly reported barriers to the uptake of psychological treatment [65], students who have been emotionally abused or maltreated may prefer this alternative to face-to-face services, although the acceptability of this approach needs to be examined. Finally, as high school is the period in which most South African university students first experience mental health problems [6], any efforts to reduce the effects of maltreatment on CMD outcomes among young people should also include interventions within the school system.

There are several limitations to consider when interpreting these findings. While this study had a relatively low response rate, post-stratification weighting increases our confidence in these results being representative of the firstyear student population at these two institutions. However, the sample was drawn from two well-resourced urban universities in the Western Cape Province which may restrict the generalisability of findings. Second, maltreatment was assessed retrospectively via self-report; recall and response biases may have led to maltreatment prevalence being underestimated. Third, as these analyses were limited to those variables included in the WMH-ICS project, we were not able to examine the association between maltreatment and 12 month prevalence of psychotic disorders nor were we able to control for the potential confounding effect of socio-economic disadvantage. We also do not know the specific ages of exposure to the various types of maltreatment, creating the potential for reverse causation. This is unlikely, given that the median age of CMD onset in our sample is 15 years [6], which is substantially older than age at which childhood maltreatment first occurs in the population [20,45]. Future studies should inquire about the age at which maltreatment occurred to ensure that this was before first CMD onset. Additionally, this study did not consider the frequency, timing, sequencing, or chronicity of maltreatment or the context in which maltreatment occurred. Including these dimensions in future studies will enhance our understanding of the relationship between maltreatment and CMDs. Due to small cell sizes for some of the maltreatment types and CMD outcomes, we did not examine patterns separately for men and women. As men and women may react differently to childhood maltreatment, future studies should investigate this further. Finally, these cross-sectional data precluded us from modelling relationships between childhood maltreatment, recent stressors and adversities, current CMD diagnoses and academic performance. Longitudinal studies that allow for the temporal relationships between these variables to be examined may identify modifiable targets for interventions and provide the evidence needed to convince university managers to invest in student mental health services.

\section{Conclusion}

Findings from this study contribute to a growing body of research on the relationship between child maltreatment and the mental health of young South Africans. Our findings not only confirm the high prevalence of childhood maltreatment among South African students, but demonstrate that maltreatment increases risk of CMDs, especially MDD, GAD and DUD. Although the effects of emotional maltreatment are generally discounted, emotional abuse was the only form of maltreatment independently associated with these CMD outcomes. Emotional abuse often co-occurred with physical abuse, yet exposure to this additional form of abuse did not seem to confer greater risk of CMDs. These findings add to the literature by identifying child maltreatment as a target for interventions aimed at reducing risk for CMDs among students. The results also highlight that young people with a history of emotional maltreatment are a high-risk group for both internalising disorders and DUD and may benefit from trauma-focused prevention efforts that address their experiences and the potential impact of maltreatment on their well-being.

Acknowledgments We wish to thank Janine Roos and Wylene Saal for assistance with data management and data cleaning.

Funding The work herein was made possible through funding by the South African Medical Research Council via its Division of Research Capacity Development under the Mid-Career Scientist Programme (awarded to J. Bantjes) and funds received from the MRC Unit on Risk and Resilience in Mental Disorders. The research was also supported by a grant from the Ithemba Foundation (awarded to Janine Roos). The funders played no role in the design of this research project, collection of data, analysis of data, interpretation of data, or the preparation of this manuscript. 


\section{Compliance with ethical standards}

Conflict of interest The authors declare that they have no conflicts of interest.

Ethics approval and consent to participate This study has been approved by the appropriate ethics committee and has therefore been performed in accordance with the ethical standards laid down in the 1964 Declaration of Helsinki and its later amendments. The Health Science Research Ethics Committee of the University of Cape Town (Reference: 744/2015) and Stellenbosch University (Reference: N13/10/149) approved this study. Permission to conduct the study was obtained from both universities. Participation in the study was entirely voluntary and participants provided informed consent electronically prior to completing the survey. A phone number to a general study helpdesk was included in the electronic informed consent to address study-related questions. All participants were provided with information about crisis and student counselling services and where to access emergency care if they were distressed. All data were anonymised and securely stored.

Availability of data and material Due to ethical restrictions, the data cannot be made publicly available. The datasets used and/or analysed during the current study are available from the corresponding author on reasonable request.

\section{References}

1. Arnett JJ (2000) Emerging adulthood: a theory of development from the late teens through the twenties. Am Psychol 55:469-480

2. McGorry PD, Purcell R, Goldstone S, Amminger GP (2011) Age of onset and timing of treatment for mental and substance use disorders: implications for preventive intervention strategies and models of care. Current Opin Psychiatry 24:301-306

3. Stallman HM (2010) Psychological distress in university students: a comparison with general population data. Australian Psychologist 45:249-257

4. Larcombe W, Finch S, Sore R et al (2016) Prevalence and sociodemographic correlates of psychological distress among students at an Australian university. Studies in Higher Education 41:1074-1091

5. Ibrahim AK, Kelly SJ, Glazebrook C (2013) Socioeconomic status and the risk of depression among UK higher education students. Soc Psychiatry PsychiatrEpidemiol 48:1491-1501

6. Bantjes J, Lochner C, Saal W et al (2019) Prevalence and sociodemographic correlates of common mental disorders among first-year university students in post-apartheid South Africa: implications for a public mental health approach to student wellness. BMC public health 19:922. https://doi.org/10.1186/s1288 9-019-7218-y

7. Herman AA, Stein DJ, Seedat S, Heeringa SG, Moomal H, Williams DR (2009) The South African stress and health (SASH) study: 12 month and lifetime prevalence of CMDs. South African Med J 99:339-344

8. Alonso J, Mortier P, Auerbach RP et al (2018) Severe role impairment associated with mental disorders: results of the WHO world mental health surveys international college student project. Depress Anxiety 35:802-814

9. Bruffaerts R, Mortier P, Kiekens G, Auerbach RP, Cuijpers P, Demyttenaere K, Green JG, Nock MK, Kessler RC (2018) Mental health problems in college freshmen: Prevalence and academic functioning. J Affect Disord 225:97-103
10. Eisenberg D, Golberstein E, Hunt JB, Eisenberg D, Golberstein E, Hunt JB (2009) Mental health and academic success in college. B E J Econ Anal Policy 9:1-35

11. Pillay N, Ramlall S, Burns JK (2016) Spirituality, depression and quality of life in medical students in KwaZulu-Natal. South Afr J Psychiatry. 22(1). Retrieved from from: https://sajp.org. za/index.php/sajp/article/view/731/588

12. Auerbach RP, Moriter P, Bruffaerts R et al (2018) WHO world mental health surveys international college student project: prevalence and distribution of mental disorders. J AbnormPsychol 127:623-638

13. McLafferty M, Lapsley CR, Ennis E et al (2017) Mental health, behavioural problems and treatment seeking among students commencing university in Northern Ireland. PLoS ONE 12:1299-1307

14. Mortier P, Demyttenaere K, Auerbach RP et al (2015) The impact of lifetime suicidality on academic performance in college freshmen. J Affect Disord 186:254-260

15. Mortier P, Cuijpers P, Kiekens G et al (2018) The prevalence of suicidal thoughts and behaviours among college students: a meta-analysis. Psychol Med 48:554-565

16. Hawton K, Saunders KE, O'Connor RC (2012) Self-harm and suicide in adolescents. Lancet 379:2373-2382

17. Cuijpers P, Auerbach RP, Benjet C, Bruffaerts R, Ebert D, Karyotaki E, Kessler RC (2019) The world health organization world mental health international college student initiative: an overview. Int J Methods Psychiatr Res 28:e1761. https://doi. org $/ 10.1002 / \mathrm{mpr} .1761$

18. Das-Munshi J, Lund C, Mathews C, Clark C, Rothon C, Stansfeld S (2016) Mental health inequalities in adolescents growing up in post-apartheid south africa: cross-sectional survey. SHaW Study PLoS One 11:e0154478. https://doi.org/10.1371/ journal.pone. 0154478

19. Finkelhor D, Shattuck A, Turner H, Hamby S (2013) Improving the adverse childhood experiences study scale. JAMA Pediatr 167(1):70-75

20. Slopen N, Williams DR, Seedat S, Moomal H, Herman A, Stein DJ (2010) Adversities in childhood and adult psychopathology in the South Africa stress and health study: associations with first-onset DSM-IV disorders. SocSci Med 71:1847-1854

21. Patten SB, Wilkes TC, Williams JV, Lavorato DH, El-Guebaly N, Wild TC, Colman I, Bulloch AG (2016) Childhood adversity and subsequent mental health status in adulthood: screening for associations using two linked surveys. EpidemiolPsychiatrSci $25: 160-170$

22. Kisely S, Abajobir AA, Mills R, Strathearn L, Clavarino A, Najman JM (2018) Child maltreatment and mental health problems in adulthood: birth cohort study. Br J Psychiatry 213:698-703

23. Subramaniam M, Abdin E, Seow E, Vaingankar JA, Shafie S, Shahwan S, Lim M, Fung D, James L, Verma S, Chong SA (2020) Prevalence, socio-demographic correlates and associations of adverse childhood experiences with mental illnesses: results from the singapore mental health study. Child Abuse Negl 103:104447

24. Gardner MJ, Thomas HJ, Erskine HE (2019) The association between five forms of child maltreatment and depressive and anxiety disorders: a systematic review and meta-analysis. Child Abuse Neg1 96:104082. https://doi.org/10.1016/j.chiabu.2019.104082

25. McLaughlin KA, Green JG, Gruber MJ et al (2010) Childhood adversities and adult psychiatric disorders in the national comorbidity survey replication II: associations with persistence of DSMIV disorders. Arch Gen Psychiatry 67:124-132

26. Nanni V, Uher R, Danese A (2012) Childhood maltreatment predicts unfavorable course of illness and treatment outcome in depression: a meta-analysis. Am J psychiatry 169:141-151 
27. Lindert J, Von Ehrenstein OS, Grashow R et al (2014) Sexual and physical abuse in childhood is associated with depression and anxiety over the life course: systematic review and meta-analysis. Int J Public Health 59:359-372

28. Infurna MR, Reichl C, Parzer P et al (2016) Associations between depression and specific childhood experiences of abuse and neglect: a meta-analysis. J Affect Disord 190:47-55

29. Martins CM, Von Werne BC, Tofoli SM, Juruena MF (2014) Emotional abuse in childhood is a differential factor for the development of depression in adults. J NervMent Dis 202:774-782

30. Humphreys K, LeMoult J, Wear JG, Piersiak HA, Lee A, Gotlib IH (2020) Child maltreatment and depression: a meta-analysis of studies using the childhood trauma questionnaire. Child Abuse Negl 102:104361

31. Mills R, Scott J, Alati R, O'Callaghan M, Najman JM, Strathearn L (2013) Child maltreatment and adolescent mental health problems in a large birth cohort. Child Abuse Negl 37:292-302

32. Afifi TO, Henriksen CA, Asmundson GJ, Sareen J (2012) Childhood maltreatment and substance use disorders among men and women in a nationally representative sample. Can J Psychiatry 57:677-686

33. Myers B, McLaughlin KA, Wang S, Blanco C, Stein DJ (2014) Associations between childhood adversity, adult stressful life events, and past year drug use disorders in the national epidemiological study of alcohol and related conditions (NESARC). Psychol Addict Behav 28:1117-1126

34. Hailes HP, Yu R, Danese A, Fazel S (2019) Long-term outcomes of childhood sexual abuse: an umbrella review. The Lancet Psychiatry 6:830-839

35. Norman RE, Byambaa M, De R, Butchart A, Scott J, Vos T (2012) The long-term health consequences of child physical abuse, emotional abuse, and neglect: a systematic review and meta-analysis. PLoS Medicine 9:e1001349. https://doi.org/10.1371/journ al.pmed.1001349

36. Berzenski SR, Yates TM (2011) Classes and consequences of multiple maltreatment: a person-centered analysis. Child Maltreat $16: 250-261$

37. Rivera PM, Fincham FD, Bray BC (2018) Latent classes of maltreatment: a systematic review and critique. Child Maltreat 23:3-24

38. Warmingham JM, Handley ED, Rogosch FA, Manly JT, Cicchetti D (2019) Identifying maltreatment subgroups with patterns of maltreatment subtype and chronicity: a latent class analysis approach. Child Abuse Negl 87:28-39

39. Debowska A, Willmott D, Boduszek D, Jones AD (2017) What do we know about child abuse and neglect patterns of co-occurrence? A systematic review of profiling studies and recommendations for future research. Child Abuse Negl 70:100-111

40. Hughes K, Bellis MA, Harcastle KA et al (2017) The effect of multiple adverse childhood experiences on health: a systematic review and meta-analysis. The Lancet Public Health 2:e356-e366. https://doi.org/10.1016/S2468-2667(17)30118-4

41. Hahm HC, Lee Y, Ozonoff A, Van Wert MJ (2010) The impact of multiple types of child maltreatment on subsequent risk behaviors among women during the transition from adolescence to young adulthood. J Youth Adolesc 39:528-540

42. Lee H, Kim Y, Terry J (2020) Adverse childhood experiences (ACEs) on mental disorders in young adulthood: latent classes and community violence exposure. Prev Med 134:106039. https ://doi.org/10.1016/j.ypmed.2020.106039

43. Ho GWK, Bressington D, Karatzias T, Chien WT, Inoue S, Yang PJ, Chan ACY, Hyland P (2020) Patterns of exposure to adverse childhood experiences and their associations with mental health: a survey of 1346 university students in East Asia. Soc Psychiatry PsychiatrEpidemiol 55:339-349
44. Merians AN, Baker MR, Frazier P, Lust K (2019) Outcomes related to adverse childhood experiences in college students: comparing latent class analysis and cumulative risk. Child Abuse Negl 87:51-64

45. Artz L, Burton P, Ward CL, et al (2016) Optimus study South Africa: technical report. Sexual victimization of children in South Africa: Final report of the Optimus Foundation Study. Zurich, South Africa: UBS Optimus Foundation. Retrieved from http://www.cjcp.org.za/uploads/2/7/8/4/27845461/08_cjcp_ report_2016_d.pdf

46. Demyttenaere K, Bruffaerts R, Posada-Villa J et al (2004) Prevalence, severity, and unmet need for treatment of mental disorders in the world health organization world mental health surveys. JAMA 291:2581-2590

47. Kessler RC, Üstün BB (2004) The world mental health (WMH) survey initiative version of the World Health Organization (WHO) composite international diagnostic interview (CIDI). Int J Methods Psychiatr Res 13:93-117

48. Felitti VJ, Anda RF, Nordenberg D et al (1998) Relationship of childhood abuse and household dysfunction to many of the leading causes of death in adults-impact on children. Am J Prev Med 14:14. https://doi.org/10.1016/S0749-3797(98)00017-8

49. Kessler RC, McLaughlin KA, Green JG et al (2010) Childhood adversities and adult psychopathology in the WHO world mental health surveys. Br J Psychiatry 197:378-385

50. Mortier P, Kiekens G, Auerbach RP, Cuijpers P et al (2017) A risk algorithm for the persistence of suicidal thoughts and behaviors during college. The J Clin Psychiatry 78:e828-e836. https://doi. org/10.4088/JCP. $17 \mathrm{~m} 11485$

51. Kessler RC, Calabrese JR, Farley PA et al (2013) Composite international diagnostic interview screening scales for DSM-IV anxiety and mood disorders. Psychol Med 43:1625-1637

52. Saunders JB, Aasland OG, Babor TF, De la Fuente JR, Grant M (1993) Development of the alcohol use disorders identification test (AUDIT): WHO collaborative project on early detection of persons with harmful alcohol consumption-II. Addiction 88:791-804

53. Ursano RJ, Colpe L, Heeringa S, Kessler R, Schoenbaum M, Stein M (2014) The Army study to assess risk and resilience in servicemembers (Army STARRS). Psychiatry InterpersBiol Process 77:107-119

54 Holt D, Smith T (1979) Post stratification. J Royal Statist Soc Series A (General) 142(1):33-46 ((Muthén LK, Muthén BO Mplus user's guide. Los Angeles, CA: Muthén \& Muthén; 1998-2014))

55. Nylund KL, Asparouhov T, Muthen B (2007) Deciding on the number of classes in latent class analysis and growth mixture modeling: a Monte Carlo Simulation Study. StructEqu Model 14:535-569

56. Bruce LC, Heimberg RG, Blanco C, Schneier FR, Liebowitz MR (2012) Childhood maltreatment and social anxiety disorder: implications for symptom severity and response to pharmacotherapy. Depress anxiety 29:131-138

57. van Harmelen AL, de Jong PJ, Glashouwer KA et al (2010) Child abuse and negative explicit and automatic self-associations: the cognitive scars of emotional maltreatment. Behav Res Ther 48:486-494

58. Wright MO, Crawford E, Del Castillo D (2009) Childhood emotional maltreatment and later psychological distress among college students: the mediating role of maladaptive schemas. Child Abuse Negl 33:59-68

59. Wills TA, Simons JS, Sussman S, Knight R (2016) Emotional selfcontrol and dysregulation: a dual-process analysis of pathways to externalizing/internalizing symptomatology and positive wellbeing in younger adolescents. Drug Alcohol Depend 163:S37-45 
60. Hobkirk AL, Watt MH, Myers B, Skinner D, Meade CS (2016) A qualitative study of methamphetamine initiation in Cape Town, South Africa. Int J Drug Policy 30:91-106

61. Bantjes J, Saal W, Lochner C et al (2020) Inequality and mental healthcare utilisation among first-year university students in South Africa. Int J Mental health syst 14:5. https://doi.org/10.1186/ s13033-020-0339-y

62. Spek V, Cuijpers P, NykIíček I, Riper H, Keyzer J, Pop V (2007) Internet-based cognitive behaviour therapy for symptoms of depression and anxiety: a meta-analysis. Psychol Med 37:319-328

63. Andersson G, Cuijpers P, Carlbring P, Riper H, Hedman E (2014) Guided internet-based vs. face-to-face cognitive behavior therapy for psychiatric and somatic disorders: a systematic review and meta-analysis. World Psychiatry 13:288-295

64. Myers B, Carney T, Johnson K, Browne A, Wechsberg WM (2020) Service providers' perceptions of barriers to the implementation of trauma-focused substance use services for women in Cape Town, South Africa. Int J Drug Policy 75:102628. https ://doi.org/10.1016/j.drugpo.2019.102628

65. Watt MH, Myers B, Towe SL, Meade CS (2015) The mental health experiences and needs of methamphetamine users in Cape Town: a mixed-methods study. South Afr Med J 105(8):685-688 